Supporting Information

\title{
The Green Method in Water Management: Electron Beam Treatment
}

\author{
Alexander V. Ponomarev and Boris G. Ershov \\ A.N. Frumkin Institute of Physical Chemistry and Electrochemistry, Russian Academy of \\ Sciences, Leninsky Prospect, 31, Moscow 119071, Russia \\ Corresponding author's email address: ershov@ipc.rssi.ru \\ 2 sections \\ 16 figures \\ 44 references \\ 21 pages
}




\section{Table of Contents}

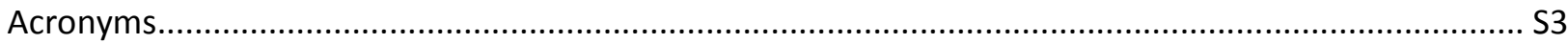

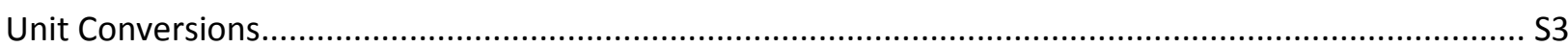

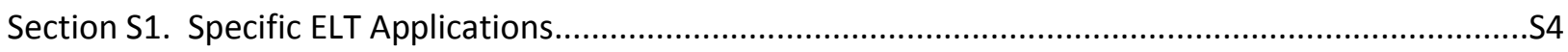

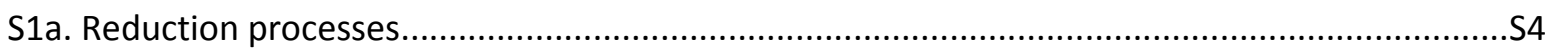

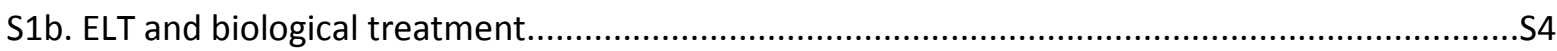

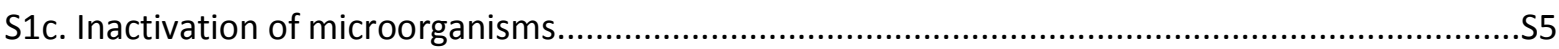

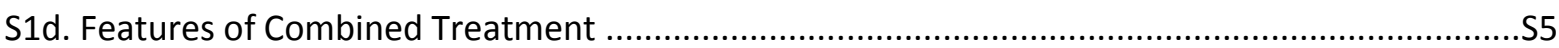

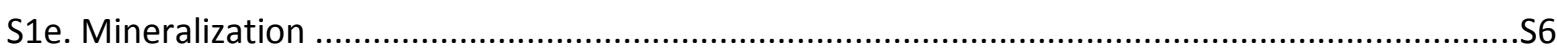

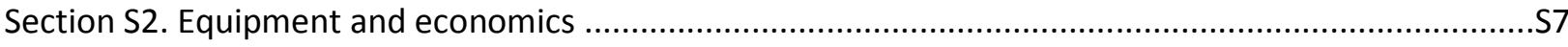

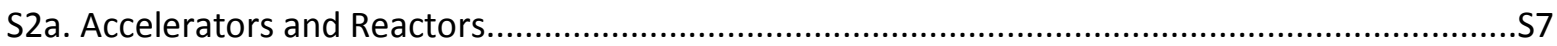

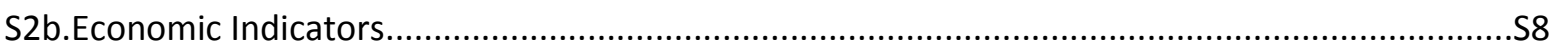

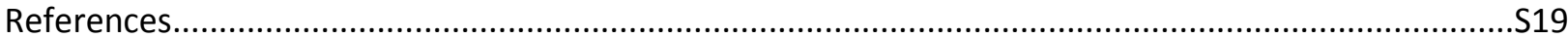

\section{List of Figures}

Figure S1. The most important processes involving ions and radicals in irradiated aqueous solutions.S10

Figure S2. The most important processes involving excited $A$ * and super-excited $A B$ ** particles in irradiated aqueous solutions.

Figure S3. The formation and properties of the most important oxidizing radicals.............................S11

Figure S4. The formation and properties of the most important radical reducing agents......................S11

Figure S5. The main processes of interconversion of oxidative and reducing intermediate

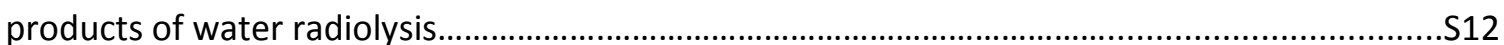

Figure S6. The ratio of $\mathrm{BOD}_{20}$ to $\mathrm{COD}_{\mathrm{Cr}}$ for organic pollutants in water ................................................... 12

Figure S7. Concentrations of some of the most common pathogens in water bodies..........................S13

Figure S8. Contaminated water treatment methods................................................................... 14

Figure S9. The relative position of the accelerator and the flow of water at low (a) and high (b) flow rates; key dimensions of the accelerator beam window (c)

Figure S10. Multi-tube (a), multi-section (b) and multi-window (c) accelerator arrangements.

HVG - high voltage generator; ATV - accelerating tube in a special vessel; ED - extraction device; BW - beam window

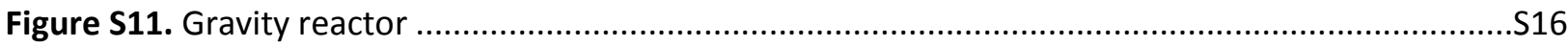

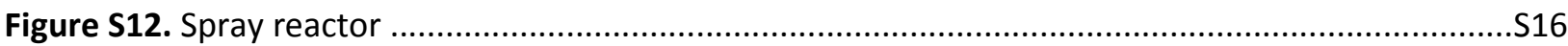

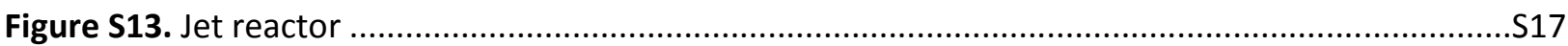

Figure S14. Schemes of a cylindrical reactor for the MWA accelerator with vertical beam scanning:

a - when the directions of water jet and beam scanning coincide (vertical section,

$B=8-12 \mathrm{~m}) ; \mathrm{b}, \mathrm{c}-$ when the directions of water jets and beam scanning intersect,

$\mathrm{b}$ - unidirectional jets (top view, $B=20 \mathrm{~m}$ ) and bidirectional jets (c, top view, $B=40 \mathrm{~m}$ )

Figure S15. Capital expenditures for the accelerator, main premises and reaction equipment, depending on the power of the accelerator $W$

Figure S16. Annual running costs depending on the power of the accelerator $W$ 


\section{Acronyms}

\section{Abbreviation: Explanation}

ELT: ELectron beam Treatment

AOTs: Advanced Oxidation Technologies

COD: Chemical Oxygen Demand

BOD: Biochemical Oxygen Demand

DC: Direct Current

MTA: Multi-Tube Arrangement

MSA: Multi-Sectional Arrangement

MWA: Multi-Window Arrangement

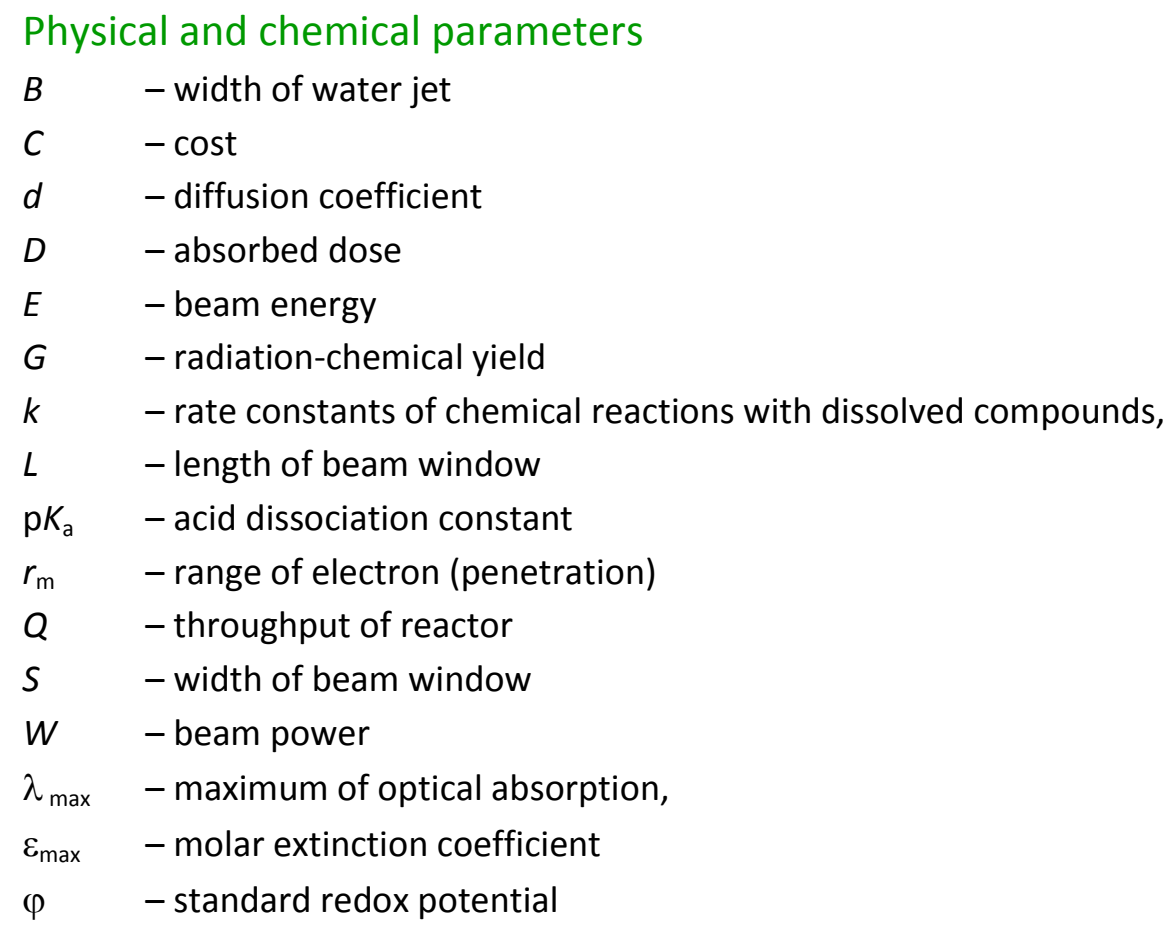

\section{Unit Conversions}

$1 \mathrm{eV}=1.60210^{-19} \mathrm{~J}$

$1 \mathrm{~Gy}=1 \mathrm{~J} \mathrm{~kg}^{-1}$

$1 \mu \mathrm{mol} \mathrm{J}^{-1}=0.1036$ molecules per $100 \mathrm{eV}$ 


\section{Section S1. Specific ELT Applications}

\section{S1a. Reduction processes}

ELT reduction of pollutants by $\mathrm{e}_{\mathrm{aq}}^{-}$and ${ }^{\bullet} \mathrm{H}$ is advisable to apply only in the following specific cases:

1. When the redox potential of the pollutant is close to the redox potential of oxygen, that is, when the pollutant itself is a strong oxidizing agent (chlorine, permanganate, etc.). So, for example, it is advisable to reduce elemental chlorine to a chloride ion, which is quite stable in contact with oxygen.

2. When the reduced form of the pollutant is a gaseous product that is easily released from water. For example, nitrite ions can be reduced to elemental nitrogen. In particular, this may explain the conversion of various nitrogen compounds to elemental nitrogen as a result of microbiological reduction observed in water bodies.

3. When the reduced form of the impurity is a sparingly soluble product, or can be easily transferred to a sparingly soluble state. For example, the reduction of metal ions into a metal or a sparingly soluble salt can serve as an appropriate example.

4. When the redox process is not strictly reversible and the reduced form of the pollutant during subsequent oxidation with oxygen can give products other than its original oxidized form. For example, reduction of aromatic polynitro compounds to the corresponding polyamines. The latter, under the action of oxygen, are converted into quinoid compounds with the release of nitrogen and the formation of high molecular weight insoluble products (possibly also their oxidation with cleavage of the benzene ring).

\section{S1b. ELT and biological treatment}

The diversity of wastewater composition and the different radiolytic susceptibility of pollutants make it appropriate to discuss the sequence of application of ELT and biological treatment. On the one hand, a low concentration of pollutants at the end of bio-treatment is favorable for using a lower absorbed dose in the subsequent ELT stage. In this case, ELT is useful both to neutralize residual chemical pollutants and to inactivate residual microorganisms. However, the appropriateness of post-biological irradiation depends on the residual concentration of pollutants that can turn into suspended and / or biodegradable substances in the ELT process. In practice, many compounds are poorly degraded in biological processes; therefore, the values of BOD and COD measured after biological treatment can vary significantly. In the presence of such contaminants, a post-radiation removal of suspended solids or an additional aeration step may be required. In addition, in dilute solutions there is a risk of back reactions due to an inadequate ratio of scavengers of oxidizing and reducing intermediates.

On the other hand, at the pre-biological stage, when the concentration of pollutants is higher, radiolysis can also lead to tangible effects at relatively small doses (less than $2 \mathrm{kGy}$ ) [Woods and Pikaev, 1994]. Examples are colloid recharging, aerobic oxidation and aggregation of suspended solids. It would be prudent to maximize the use of these low dose effects. Accordingly, post-radiation biological treatment can become more efficient by facilitating the capture of suspended particles by sludge flakes and by faster aerobic degradation of pollutants. It should be noted that ELT does not directly affect microorganisms acting at the stage of subsequent bio-treatment, since radiolytic radicals disappear in reactions with each other in fractions of a second in the process of transporting water from the location of ELT to the place of bio-treatment.

Bio-treatment and sedimentation are the most common among conventional water treatment methods. Therefore, the ability of radiolysis to have a significant effect on precipitation and biodegradability is very important. However, a dilemma is emerging. On the one hand, the conversion of pollutants to biodegradable and insoluble forms leads to purer water. On the other hand, the same 
effects can result in an increase in sludge yield and an increase in air flow rate for aeration. Therefore, this dilemma in the application to ELT needs a more detailed study and understanding.

\section{S1c. Inactivation of microorganisms}

Figure S7 shows the content (number per liter) of some of the most common pathogens in water bodies. In turn, the content of these microorganisms in purified water should be limited. Most often, the use of water from natural sources for industrial purposes does not require its antimicrobial treatment, while its use as drinking water is possible only after disinfection. In particular, the number of enteric viruses, Giardia cysts, and Cryptosporidium oocysts in one liter of water prepared for drinking use should not exceed $2.2 \times 10^{-7}, 6.8 \times 10^{-6}$, and $1.7 \times 10^{-6}$, respectively. For many samples of natural water, the content of Escherichia coli has to be reduced millions of times [Montgomery, 1985; State Water Resources Control Board, 2016].

As a rule, absorbed doses of up to 5-10 kGy are needed for inactivation of pathogens in water via ELT. For example, a 10 -fold decrease in the concentration of $E$. coli is provided at $0.09-0.2 \mathrm{kGy}$ depending on the composition of water, while for some other microorganisms this dose can be up to $1.3 \mathrm{kGy}$ [IAEA, 2019; Micro D10 reference data; Okunieff et al., 2008; Woods and Pikaev, 1994]. The disinfecting effect of accelerated electrons is due to direct and indirect radiolytic damage to the DNA of microorganisms. Direct damage occurs when radiation directly affects the microorganism. In turn, indirect inactivation is caused by the reactions of short-lived products of water radiolysis with the functional groups of DNA of microorganisms. As a result of these processes, microorganisms lose their viability and reproducibility [Bae et al., 1999; Engohang-Ndong et al., 2015; IAEA, 2019; Lim and Kim, 2018; Woods and Pikaev, 1994]. Due to its high efficiency, electron-beam inactivation of microorganisms is widely used in the sterilization of medical devices, food, cosmetics, etc. [IAEA \& IIA, 2011; Pikaev, 2001; Woods and Pikaev, 1994]. Undoubtedly, the disinfecting effect of ELT should also be used in water treatment.

\section{S1d. Features of Combined Treatment}

Wastewater treatment methods are divided into two categories (Figure S8) - removal methods and transformation methods. Removal methods provide a decrease in the concentration of pollutants in the treated wastewater, while transformation methods make it possible to change the phase composition and chemical activity of impurities without changing their total content. Chemical and phase transformations are often reversible. Accordingly, from an environmental point of view, it is not enough to transform the toxic impurity into a harmless form, it should be removed from the water. This task can be solved by converting pollutants into an easily separable insoluble state - into a volatile, liquid or solid state. Therefore, transformation methods should always be combined with reliable removal methods. This provides both an irreversible decrease in the concentration of dissolved contaminants and a decrease in their harmfulness.

The designing of the ELT installation should take into account the possibility of combining various types of wastewater. In particular, this technique is advisable when the effluents have opposite chemical properties, for example, when mutual neutralization of acidic and alkaline waters occurs or organic substances are precipitated with mineral salts, etc. [Ponomarev, 2004]. The treatment of some industrial effluents (for example, from laundries, gas enterprises, hydrolysis plants, pulp and paper mills) is more effective when mixed with municipal wastewater [Pikaev et al., 2001]. On the other hand, some industrial effluents contribute to the clarification of urban wastewater and more stable operation of urban sedimentation tanks. The essence of the combined approach is to facilitate the radiolytic formation of insoluble compounds and balance the nutrient content for the subsequent stage of biological treatment. 
Mixing urban and industrial wastewater requires caution because of the significant differences in nature and concentration of pollutants. However, in the case of ELT, mixing is suitable in order to accelerate and facilitate the neutralization of pollutants. The predominance of organic compounds in one of the effluents (for example, urban) and inorganic compounds in the other (industrial), makes it possible under aerobic conditions to initiate a chain process of redox degradation of the components of both effluents and to facilitate the separation of products in the form of sediment. Thus, under the condition of the optimal combination of different wastewater, ELT makes it possible to convert the additive treatment mode into a synergistic mode [Woods and Pikaev, 1994], leading to the simplification and cheapening of treatment technology.

\section{S1e. Mineralization}

The process of radiolytic mineralization can occur both in the presence of dissolved oxygen, and in its absence. However, in the latter case, the yield of mineralization is much lower. Under anaerobic conditions, the yields of mineralization $G_{m}$ are usually lower than the total yield of degradation of the pollutant $G_{\mathrm{d}}$ and the yield of oxidizing radicals $G_{\mathrm{R}}: G_{\mathrm{R}}>G_{\mathrm{d}}>G_{\mathrm{m}}$. The values of $G_{\mathrm{m}}$ are usually no less than 3.5 and 1.8 times lower than $G_{\mathrm{R}}$ and $G_{\mathrm{d}}$, respectively [Alkhuraiji et al., 2016, 2017; Kovács et al., 2016; Paul et al., 2014]. On average, from 3 to 6 radicals are required for radiolytic removal of the methyl or methylene group by the mineralization mechanism, while only 1-2 radicals are enough to transform a molecule into a biodegradable form. The efficiency of mineralization is further weakened in the presence of inorganic anions, such as $\mathrm{Cl}^{-}, \mathrm{HCO}_{3}^{-}, \mathrm{HSO}_{4}^{-}$, which are ${ }^{\circ} \mathrm{OH}$ radical scavengers [Abdel Daiem et al., 2013; Chu and Wang, 2016; Guo et al., 2012; Zheng et al., 2011]. Mineralization may include sequential ring opening processes (for cyclic and aromatic compounds), oxidation with the formation of peroxide radicals and carboxyl compounds, as well as subsequent decarboxylation [Ershov, 2004; Makarov and Ponomarev, 2018]. The most efficient conversion to $\mathrm{CO}_{2}$ and $\mathrm{H}_{2} \mathrm{O}$ is observed during radiolytic decomposition of small organic oxygen-containing compounds - formic and oxalic acids, formates and oxalates, etc. [Pikaev, 2001; Szabó et al., 2014; Woods and Pikaev, 1994].

In the case of larger molecules with a concentration above $6 \mathrm{mg} \mathrm{dm}^{-3}$, economical mineralization can be realized only via the mechanism of chain oxidation. Adding an oxygen molecule turns the reducing radicals into oxidizing ones (Figure S5). The maximum mineralization yields are achieved under the condition of intensive aeration of the solution during irradiation [Pikaev, 2000; Podzorova, 2001]. However, in real wastewater, chain oxidation often does not occur at all due to the absence of chain propagation reactions, the presence of inhibitor impurities, etc. Moreover, the process of mineralization of organic molecules, especially complex ones, is multi-stage and, accordingly, requires the use of a relatively high absorbed dose [Makarov and Ponomarev, 2018; Pirogova et al., 2002]. Due to energy costs, the principle of electron beam mineralization is hardly suitable for large-tonnage treatment of complex wastewater, but it can be successfully used to remove hazardous impurities with a low concentration. In particular, absorbed doses of several kGy may be sufficient to remove some pharmaceutical and hygienic preparations whose concentration in water reaches hundreds of $\mu \mathrm{M} \mathrm{dm}^{-3}$ [Shen et al., 2019; Wang and Chu, 2016]. However, it should be noted that in the study of dilute aqueous solutions, the mineralization process is often confused with the formation of ultrafine particles that easily adhere to the walls and bottom of the irradiated vessel. Since ultrafine particles in highly diluted solutions are invisible to the naked eye, it is mistakenly believed that the decrease in the dissolved pollutant is due to its conversion to $\mathrm{CO}_{2}$ and $\mathrm{H}_{2} \mathrm{O}$, i.e. its mineralization. 


\section{Section S2. Equipment and economics}

\section{S2a. Accelerators and Reactors}

The electron energy $E$ determines the depth of its penetration into water (electron range). The higher $E$, the thicker the water layer can be irradiated. At $E$ up to $2.5 \mathrm{MeV}$, accelerated electrons penetrate into water to a depth $r_{\mathrm{m}}\left(\mathrm{g} \mathrm{cm}^{-2}\right)$ corresponding to $0.412 E^{n}$, where $n=1.265-0.0954 \ln (E)$ [Woods and Pikaev, 1994]. However, the most uniform irradiation is provided at a water layer thickness $r_{\mathrm{u}}=\mathrm{E} / 3 \rho$, where $\rho$ is the density $\left(\mathrm{g} \mathrm{cm}^{-3}\right)$. The value of $r_{u}$ is almost a third less than $r_{m}$. Accordingly, the desire for a uniform distribution of the absorbed dose over the volume of water is fraught with losses of almost $1 / 3$ of the beam energy. Such energy losses are irrational, especially since the electrons that penetrated the $r_{u}$ layer remain capable of ionizing and exciting water molecules and, thus, of neutralizing pollutants. At low water flow rate, intensive mixing should be used, for example, bubbling. When irradiating a highvelocity jet of $r_{\mathrm{u}}$ thickness, some of the irradiated water should be retained at the bottom of the reactor as an additional absorption layer.

The beam window is located at the end of the extraction device of the accelerator (Figure S9) and is usually an elongated rectangle up to 1-2.5 meters $(L)$ long and up to 7-40 cm wide $(S)$, made of foil. The length $L$ and width $S$ are determined by the $W$ and the beam current density (usually $\sim 70 \mu \mathrm{A} \mathrm{cm}{ }^{-2}$ ) [Chmielewski, 2012; Cleland et al., 1984; Ponomarev, 2004]. The design of the radiation-chemical reactor substantially depends on the required throughput, absorbed dose, and accelerator arrangement. In the case of a high absorbed dose $D$ and a low flow rate $Q$ of water, it is advisable to orient the beam window along the direction of the water flow (Figure S9a). This orientation will provide a longer residence time of water in the irradiation area. In the case of high $Q$ and low $D$, the longer side of the beam window should be oriented across a wide water stream (Figure S9b). The distance from the beam window to the surface of the water is determined by several parameters, such as beam geometry, turbulence of the water flow, ease of maintenance of the beam window and its cooling system. On average, this distance can be from 30 to $60 \mathrm{~cm}$.

In practice, a higher energy would allow the use of thicker jets (25 mm at $5 \mathrm{MeV}$ ), which is technologically more convenient and, moreover, requires lower beam currents. For example, a modern $500 \mathrm{~kW}, 1 \mathrm{MeV}$ accelerator is hypothetically capable of irradiating up to 5700 cubic meters of river water per hour at a dose of 500-700 Gy and a linear jet velocity of $5 \mathrm{~m} \mathrm{~s}^{-1}$. However, such a throughput is unrealistic, since 5700 cubic meters per hour corresponds to a jet width $B=34$ meters (Figure S9), while the beam scanning amplitude in a modern accelerator does not exceed $L=2.5$ meters [Kuksanov et al., 2018; Ponomarev, 2020]. Accordingly, the specified accelerator should have at least 14 beam windows. Or instead of a single $500 \mathrm{~kW}$ accelerator, 14 low-power single-window accelerators should be used, whose total cost is much higher. In turn, higher beam energy would correspond in proportion to a smaller number of beam windows and a smaller beam current.

There are three main options for equipping the accelerator with several beam windows [Ponomarev, 2020]. The first option is to use several accelerating tubes (multi-tube arrangement, MTA) powered by a single high-voltage generator (Figure S10a). However, the MTA does not provide significant savings in metal consumption and in the occupied space compared to 14 separate accelerators. There are several projects to create MTA accelerators, but only one accelerator [Kuksanov et al., 2018] has been tested in practical water treatment. Another option of the accelerator arrangement is sectioning the beam window (multi-section arrangement, MSA) - equipping the beam window with several longitudinal frame sections extracting the beam in one direction (Figure S10b). In fact, MSA is the attachment of several single windows to each other in the same plane. This option is suitable in order to use a high beam current (respectively, a high dose of radiation), but does not provide an opportunity to increase 
the flow width $B$. Currently, many powerful accelerators are equipped with a sectioned beam window [Tolstun et al., 2014]. Both the first and second options are a modification of accelerators previously developed for commercial, conveyor technologies. The third option seems more rational, but it is less commonly used in commercial practice (Figure S10c). It consists in the distribution of the beam generated in one accelerating tube between several beam windows oriented in different directions (multi-window arrangement, MWA) [Ivanov et al., 2001; Tolstun et al., 2006]. Moreover, the number of components in the MWA accelerator is much smaller than in the MTA accelerator, which is favorable from the point of view of price, dimensions, mounting and maintenance of the accelerator [Ponomarev, 2020]. Such an accelerator could be coordinated with 1 cylindrical reactor, where an annular flow of water surrounds the extraction device of the accelerator (see below).

The simplest version of the reactor (Figure S11) provides for gravity-fed water supply (gravity reactor) [Ponomarev, 2000]. In this case, water moves in the irradiation area along a horizontal, vertical or inclined path with a speed determined solely by gravity. Taking into account the resistance of structural elements, the speed does not exceed $0.5-0.6 \mathrm{~m} \mathrm{~s}^{-1}$, which makes it possible to use high absorbed doses and carry out intensive mixing using partitions, swirls and/or bubbling. Gravity reactor is suitable for combining ELT with ozonation. This type of reactor was most often used in model and pilot industrial water treatment with accelerated electrons [Pikaev, 2000; Ponomarev, 2000, 2004].

Another type of reactor (Figure S12) is designed to irradiate water in the form of an aerosol (spray reactor) [Ponomarev, 2000]. Water is injected under pressure into the irradiation area through one or more spray nozzles. The spray reactor makes it possible to achieve maximum contact of water with air and/or ozone, that is, to carry out an oxidative conversion of contaminants. The speed of the sprayed jet can be 3-5 $\mathrm{m} \mathrm{s}^{-1}$, however, water must be previously freed from suspended particles in order to avoid clogging and rapid abrasive destruction of nozzles. Water aeration should be carried out immediately before being fed into the reactor and during the spraying process, since the dissolution of oxygen and ozone inside the irradiation area is limited due to the short exposure time. The spray reactor is suitable primarily for low water flow rate. This type of reactor was first introduced to disinfect the wastewater of a medical complex in Russia [Podzorova, 2001].

The most efficient reactor (Figure S13) provides for the formation of water in the form of a wide jet, the thickness of which is consistent with the range of electrons used (jet reactor) [Ponomarev, 2000]. Due to the forced supply, the water speed can reach several meters per second [Han et al., 2005, 2012; 2016, Makarov et al., 2003]. Taking into account the abrasive effect of suspended particles, the nozzle forming a wide water jet should have a replaceable design or be made of a highly resistant material. In addition, the design of the forming nozzle should ensure equal flow rates over the entire width of the jet. At low $D$ and high $Q$, the jet reactor can be equipped with two oncoming jets, merging under the beam window of the accelerator. This type of reactor was first introduced in the Republic of Korea for electron beam treatment of $10,000 \mathrm{~m}^{3}$ per day of colored polyester wastewater [Makarov et al., 2003].

The jet mode of water supply to the irradiation area can also be used for the above MWA accelerators [Ponomarev, 2020]. In this case, water jets are directed along the walls of the cylindrical reactor (Figure S14). At $5 \mathrm{MeV}$ energy, $800 \mathrm{~mA}$ beam current (already achievable), $5 \mathrm{~m} \mathrm{~s}^{-1}$ linear jet velocity, a cylindrical reactor could provide up to 40 meters of the total jet width $B$ and, thus, have a throughput of up to 400,000 cubic meters per day. Previously tested reactor options, in combination with MTA or MSA accelerators, provided treatment of up to 10,000 cubic meters of water per day [Han et al., 2012].

\section{S2b. Economic Indicators}

Accelerator pricing is determined by market laws and substantially depends on industry purpose and, accordingly, on the accelerator arrangement. Accelerator manufacturers do not advertise specific pricing principles, but general patterns can be traced. Electron beam treatment is a continuous (flow) 
process, whose productivity is directly proportional to the beam power $W$ of the accelerator used and inversely proportional to the absorbed dose $D$ [Meeroff et al. 2019; Woods and Pikaev, 1994]. At $D=1$ $\mathrm{kGy}$, the specific treatment rate (per $1 \mathrm{~kW}$ ) is $2.7 \mathrm{~m}^{3} \mathrm{kWh}^{-1}$ or about $65 \mathrm{~m}^{3} \mathrm{~kW}^{-1}$ per day. At $W=400 \mathrm{~kW}$, this corresponds to about $26,000 \mathrm{~m}^{3}$ per day, which characterizes ELT as a large-scale water treatment method. The beam energy $E$ has the greatest impact on the cost $C$ of the accelerator and its dimensions. Usually, the dependence of $C(\$ 1,000)$ on $E(\mathrm{MeV})$ is linear or the $C$ value is proportional to the square root of $E$ (for middle power accelerators). The dependence of cost $C$ and accelerator dimensions on $W$ $(\mathrm{kW})$ is weaker. Most often, the proportions $C \sim W^{1 / 2}$ or $C \sim W^{1 / 4}$ are used. As a result, in earlier ELT projects, for the sake of cheapness, preference was given to powerful accelerators ( $W \geq 100 \mathrm{~kW})$ with relatively low energy ( $E=1-1.5 \mathrm{MeV}$ ). However, as noted above, higher energy (up to $5 \mathrm{MeV}$ ) provides more technological advantages, and also helps to reduce the number of accelerators and reaction area. In this regard, the use of the above MWA accelerators could help to improve the economic performance of ELT [Ponomarev, 2020].

A chemical reactor occupies a relatively small fraction of the cost of an ELT installation. The approximate cost ratio for the creation and operation of the ELT installation depending on $W$ is shown in Figs S15 and S16, based on the experience of using MTA and MSA accelerators for ELT in the Republic of Korea, China and Russia, where such work is carried out more often. The most significant capital expenditures are due to the cost of the accelerator and the premises (main and auxiliary) in which the installation is located. These costs largely determine the feasibility of using the ELT method [Cleland et al., 1984; Makarov and Ponomarev, 2018; Wojnárovits and Takács, 2017; Pikaev, 2000; Woods and Pikaev, 1994]. Figure S15 demonstrates that capital expenditures depend on $W$ nonlinearly: there is a decrease in specific costs with increasing accelerator power. Among operating expenses (Figure S16), the cost of electricity and spare parts is almost proportional to $W$. In turn, depreciation and other operating expenses have a weaker dependence on $W$ in accordance with the nonlinear increase in the cost of the accelerator. The salary of personnel is practically independent of $W$, since the number of operators is unchanged on an accelerator of any power. 


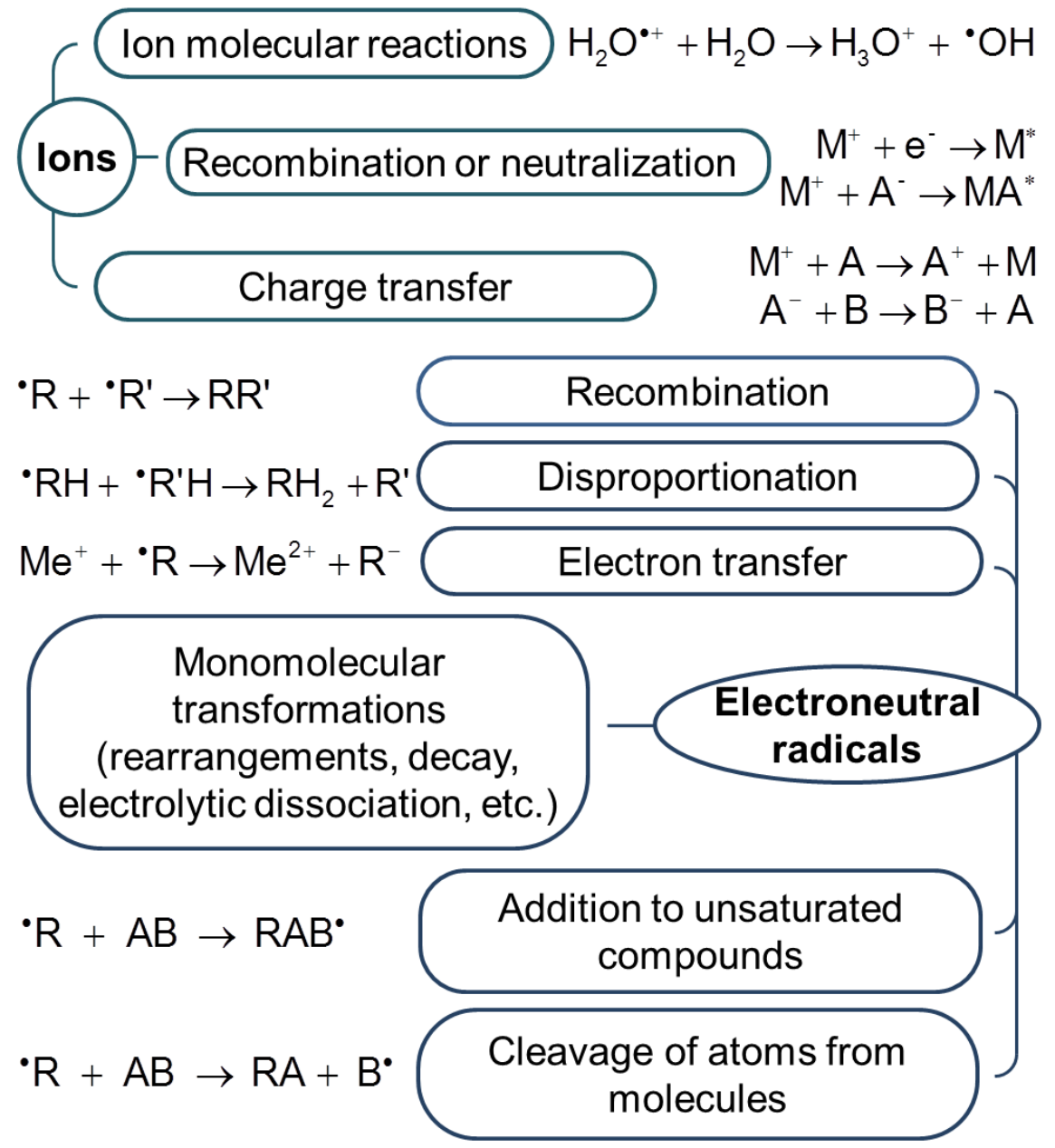

Figure S1. The most important processes involving ions and radicals in irradiated aqueous solutions

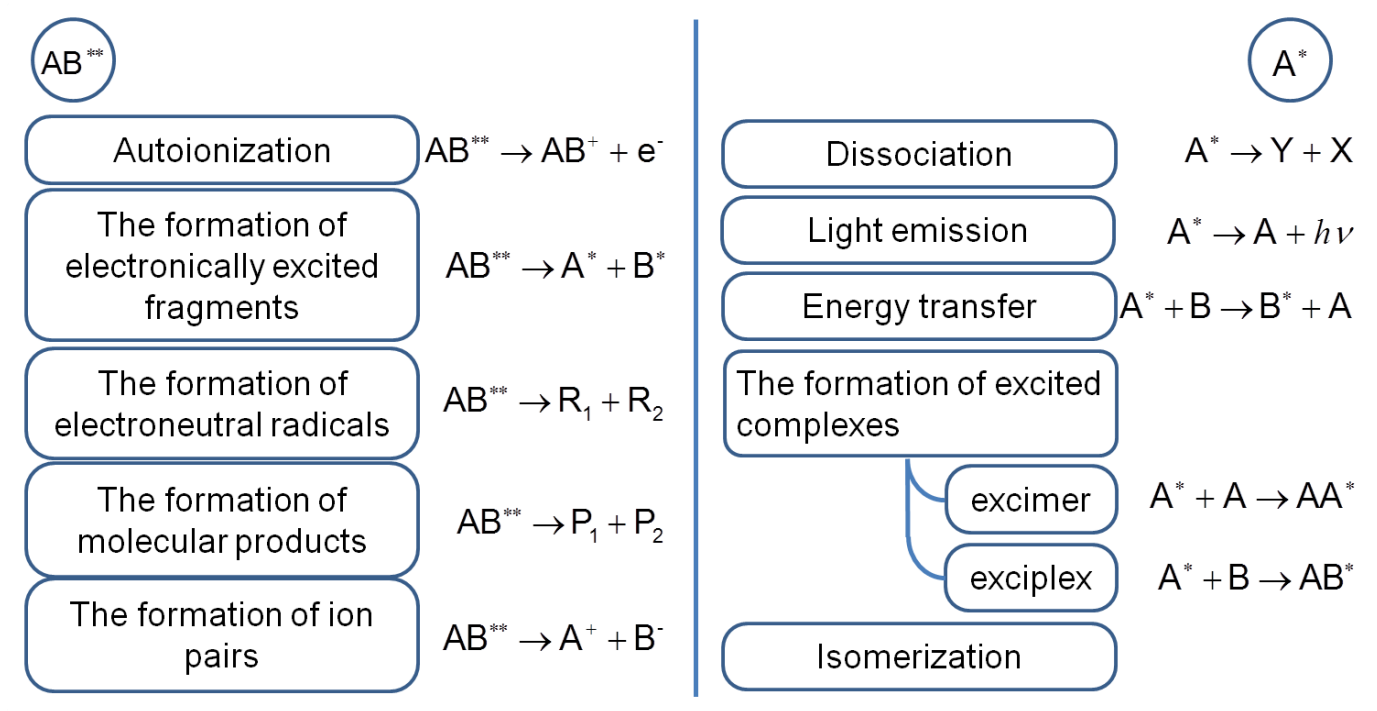

Figure S2. The most important processes involving excited $A *$ and super-excited $A B * *$ particles in irradiated aqueous solutions 


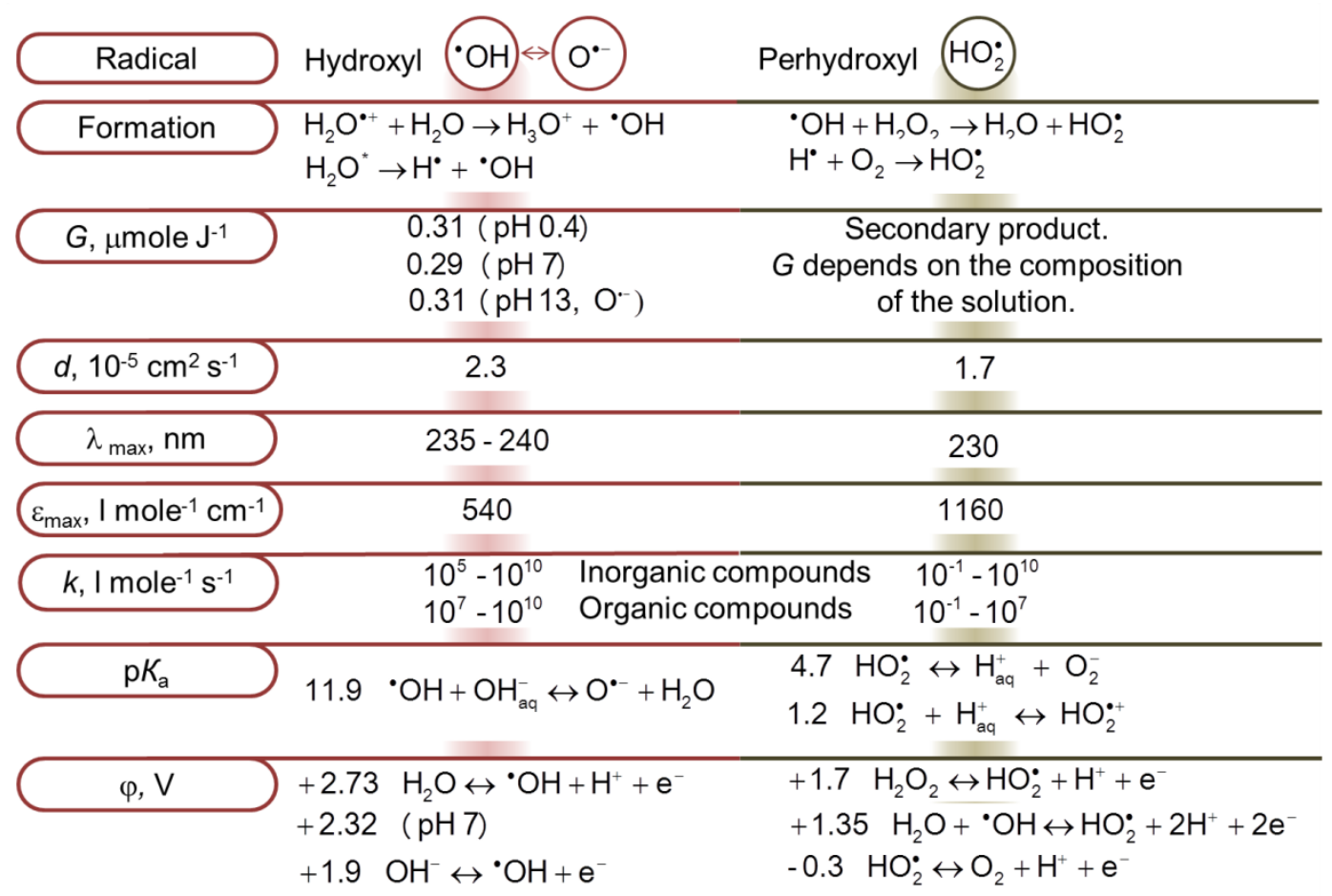

Figure S3. The formation and properties of the most important oxidizing radicals (diffusion coefficient $(d)$, maximum of optical absorption $\left(\lambda_{\max }\right)$, molar extinction coefficient $\left(\varepsilon_{\max }\right)$, typical rate constants of chemical reactions with dissolved compounds $(k)$, acid dissociation constant $\left(\mathrm{p} K_{\mathrm{a}}\right)$, standard redox potential $(\varphi))$.

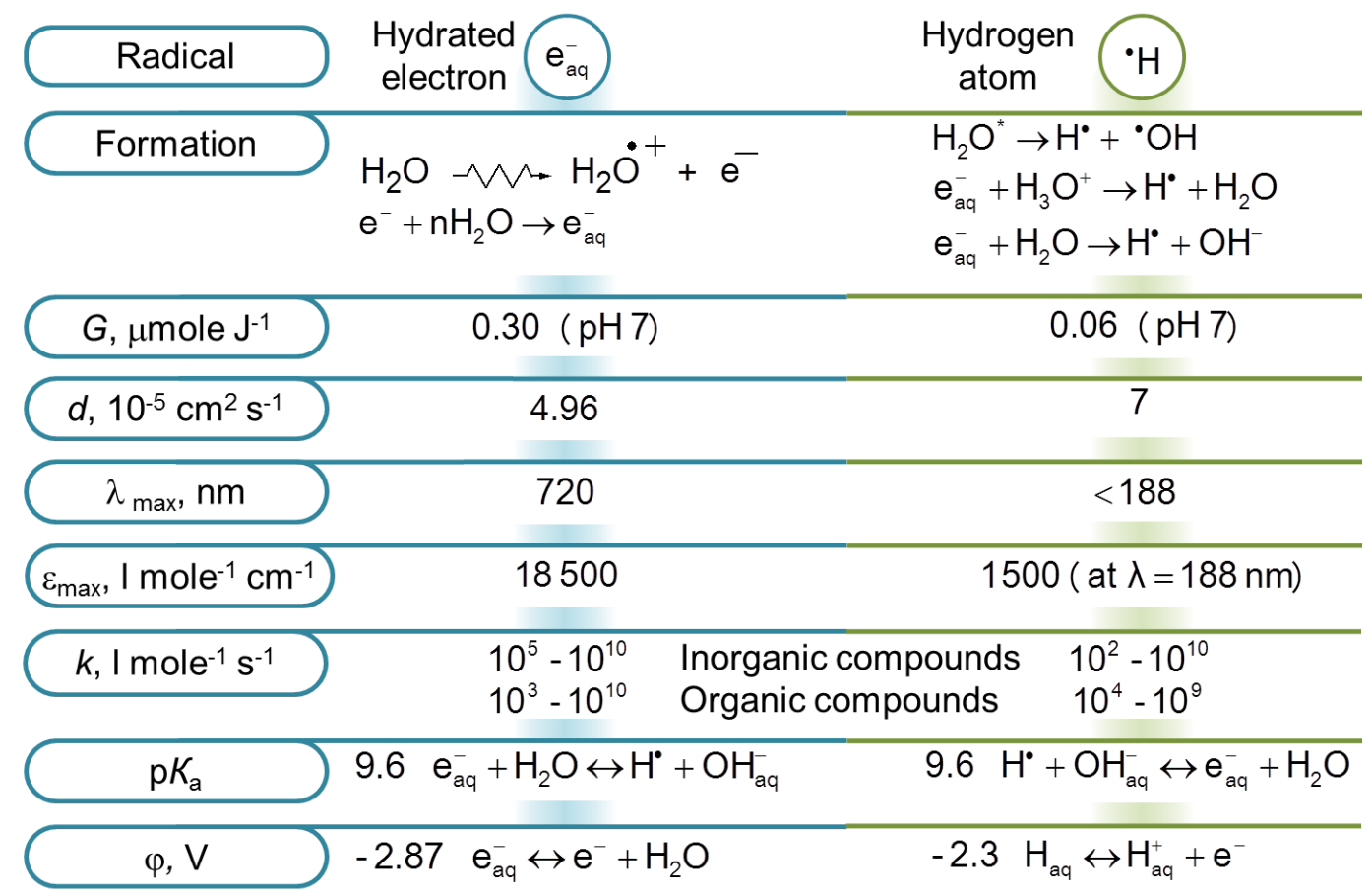

Figure S4. The formation and properties of the most important radical reducing agents (diffusion coefficient $(d)$, maximum of optical absorption $\left(\lambda_{\max }\right)$, molar extinction coefficient $\left(\varepsilon_{\max }\right)$, typical rate constants of chemical reactions with dissolved compounds $(k)$, acid dissociation constant $\left(\mathrm{p} K_{\mathrm{a}}\right)$, standard redox potential $(\varphi))$. 


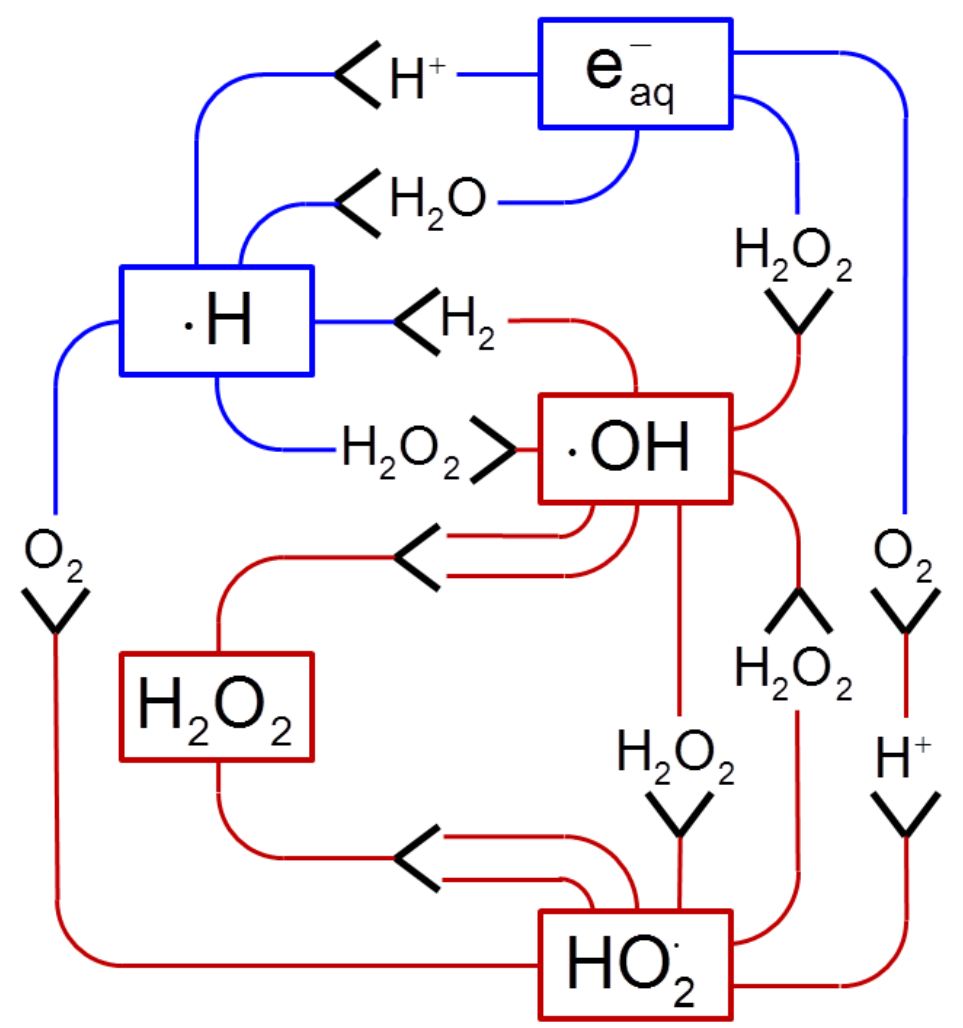

Figure S5. The main processes of interconversion of oxidative and reducing intermediate products of water radiolysis

Carboxyl compounds

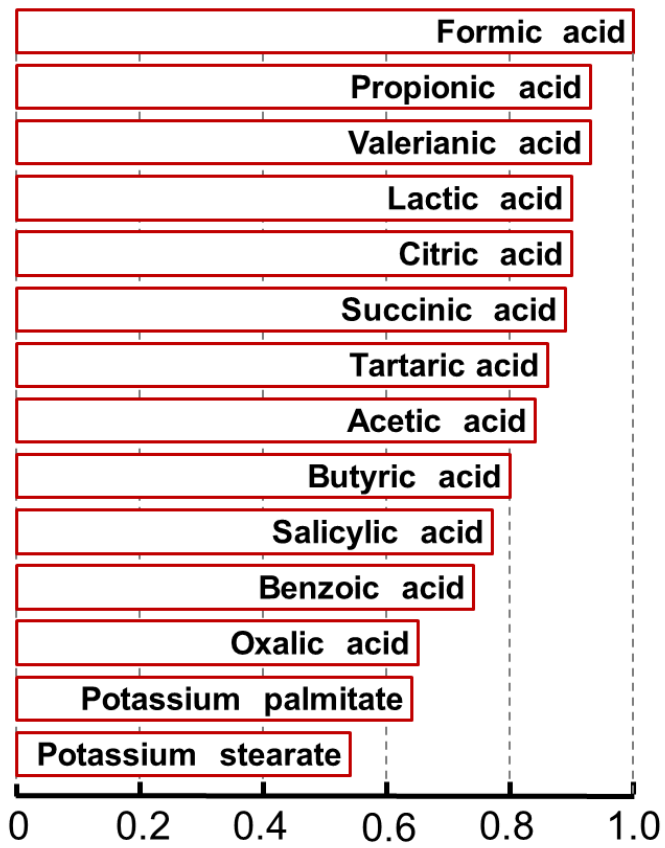

Hydroxyl compounds

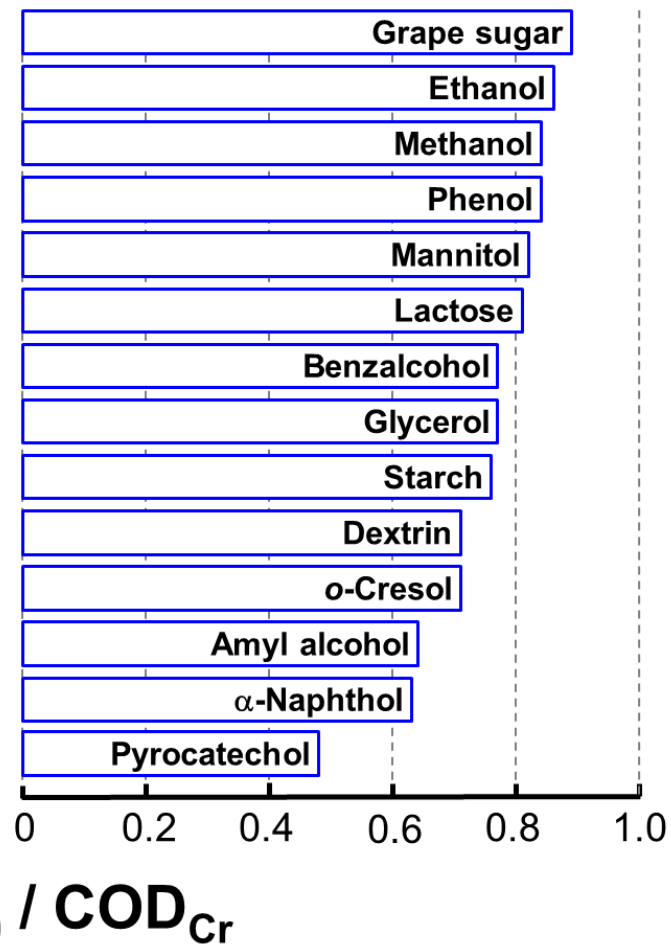

Figure S6. The ratio of $\mathrm{BOD}_{20}$ to $\mathrm{COD}_{\mathrm{Cr}}$ for organic pollutants in water 


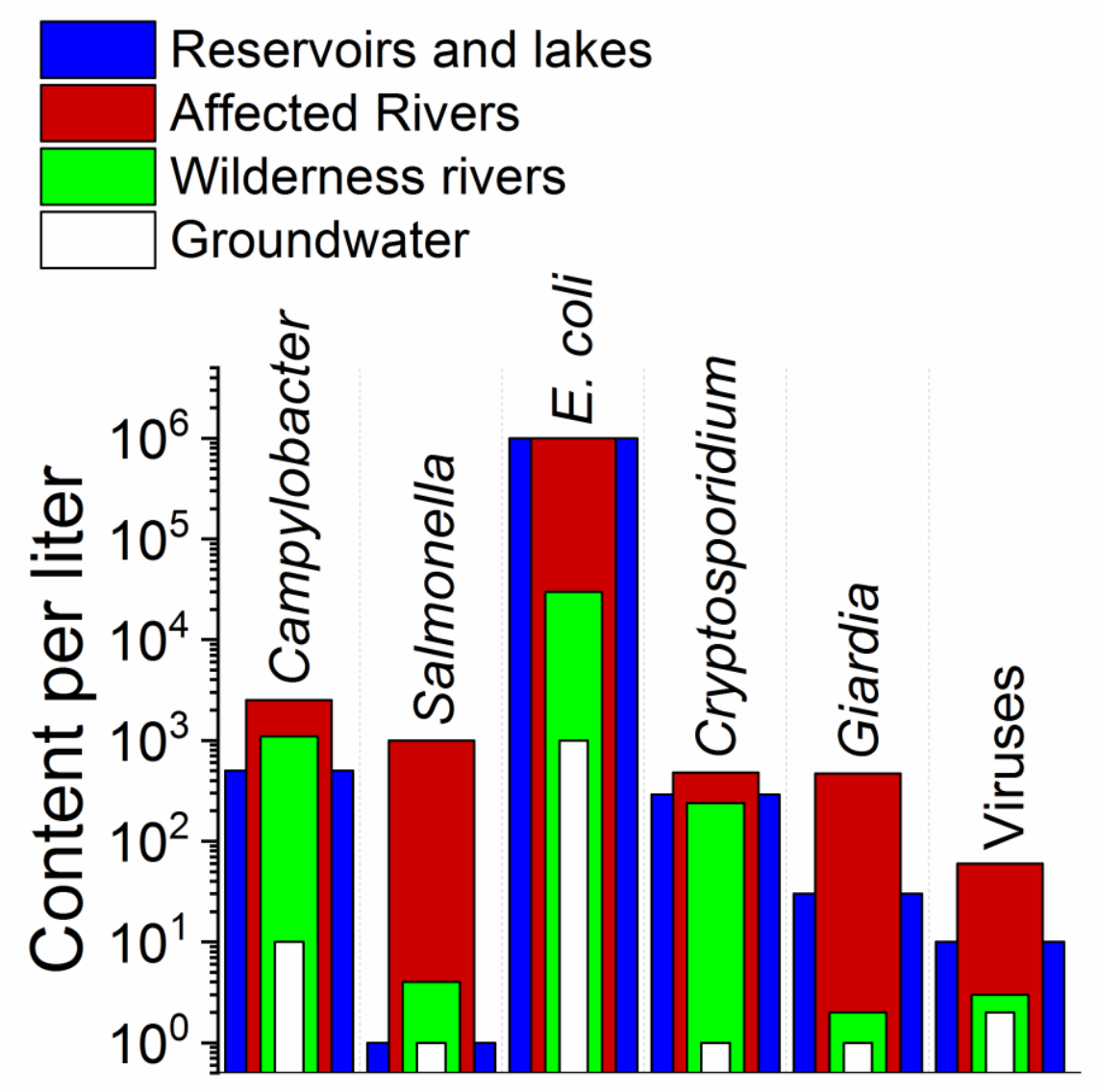

Figure S7. Concentrations of some of the most common pathogens in water bodies 


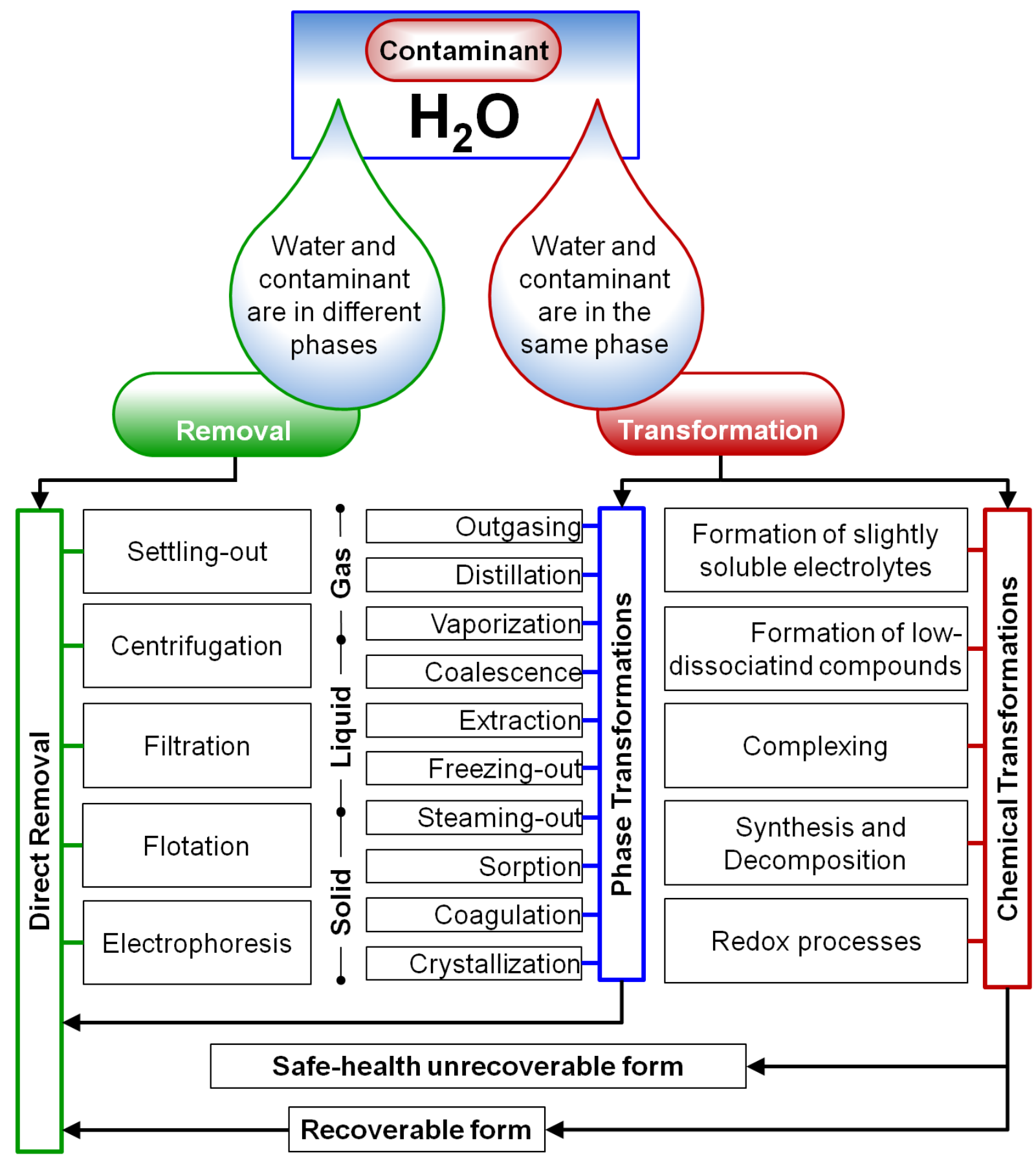

Figure S8. Contaminated water treatment methods 

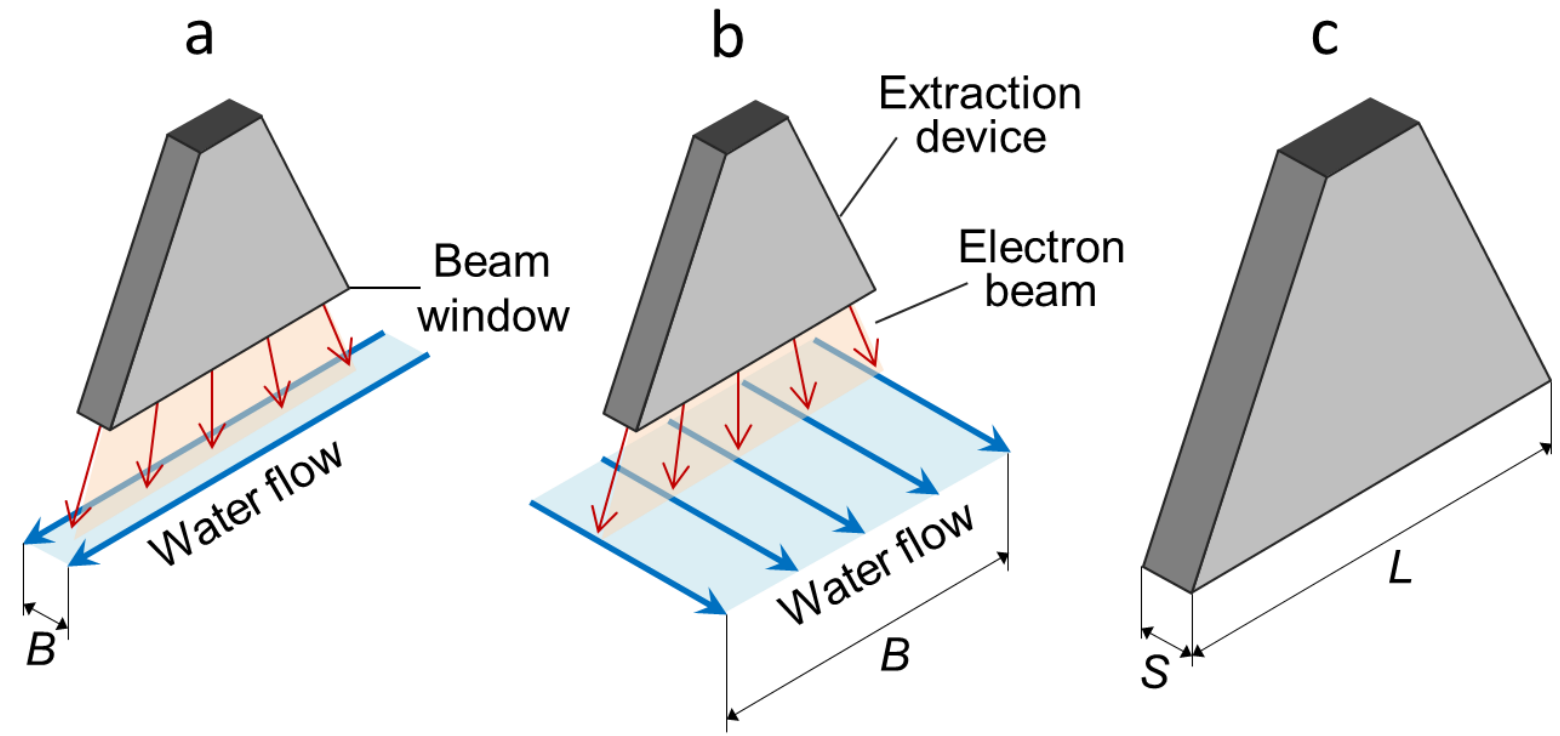

Figure 59. The relative position of the accelerator and the flow of water at low (a) and high (b) flow rates; key dimensions of the accelerator beam window (c)

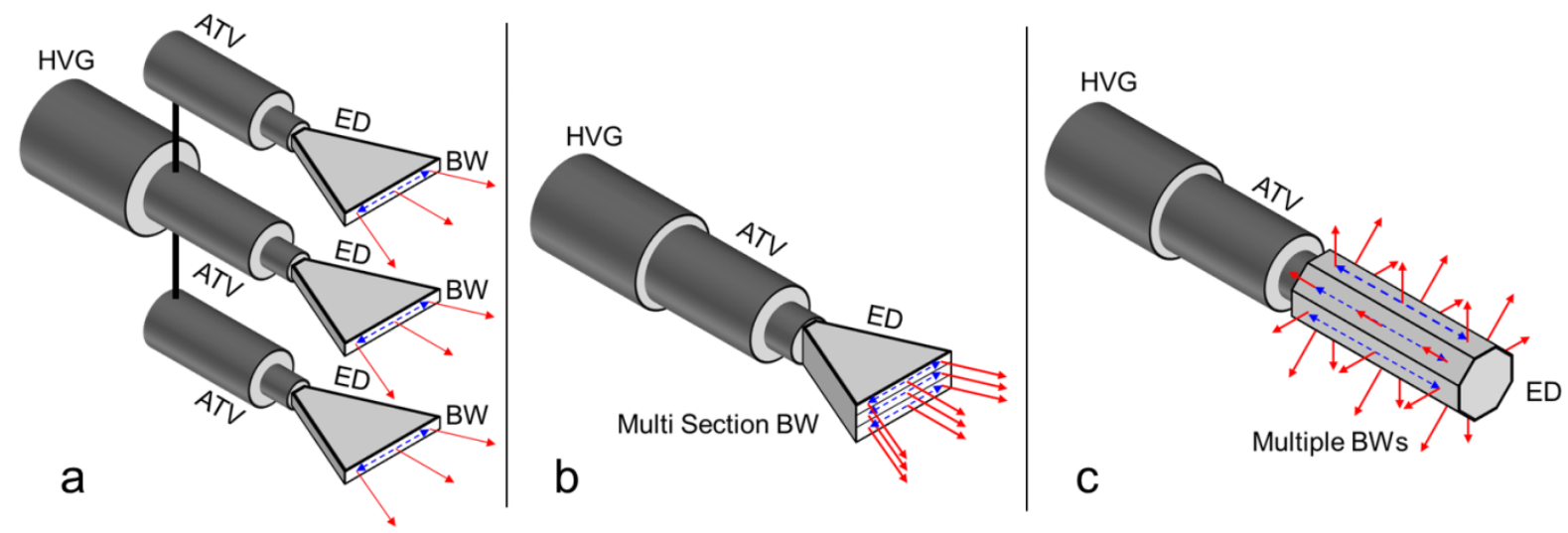

Figure S10. Multi-tube (a), multi-section (b) and multi-window (c) accelerator arrangements. HVG - high voltage generator; ATV - accelerating tube in a special vessel; ED - extraction device; BW - beam window 


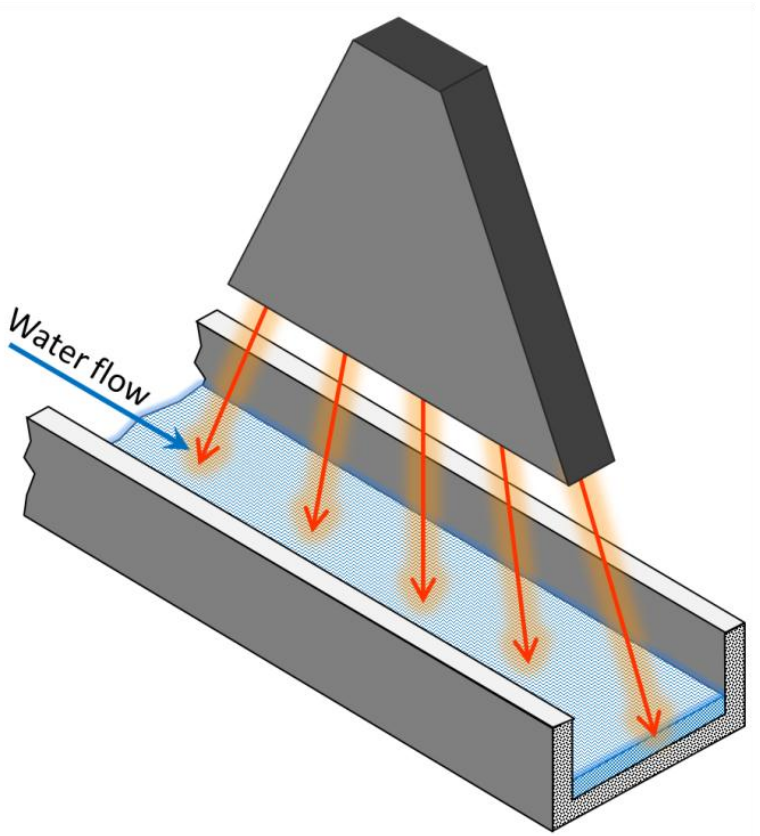

Figure S11. Gravity reactor

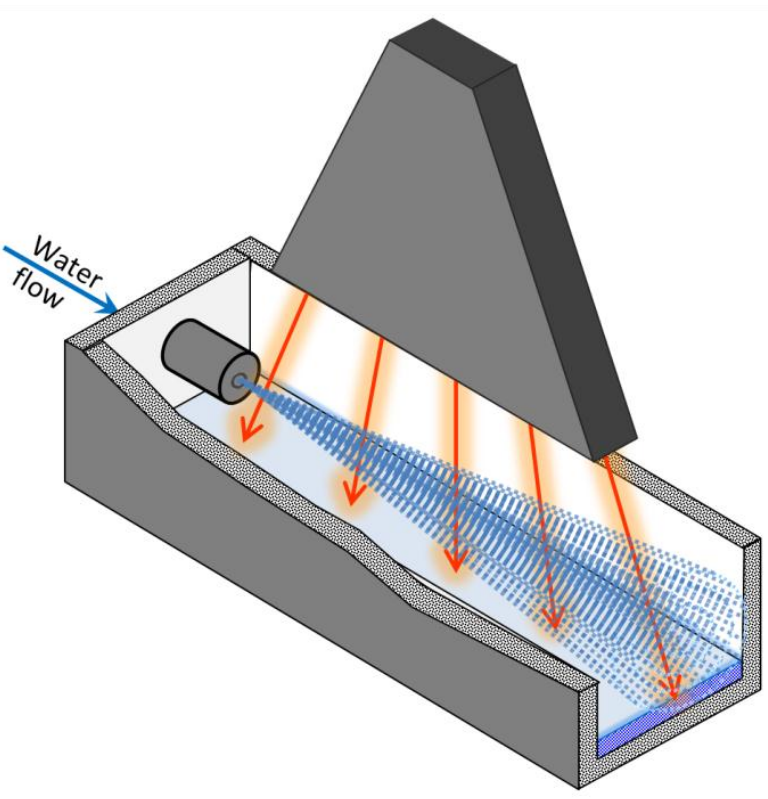

Figure S12. Spray reactor 


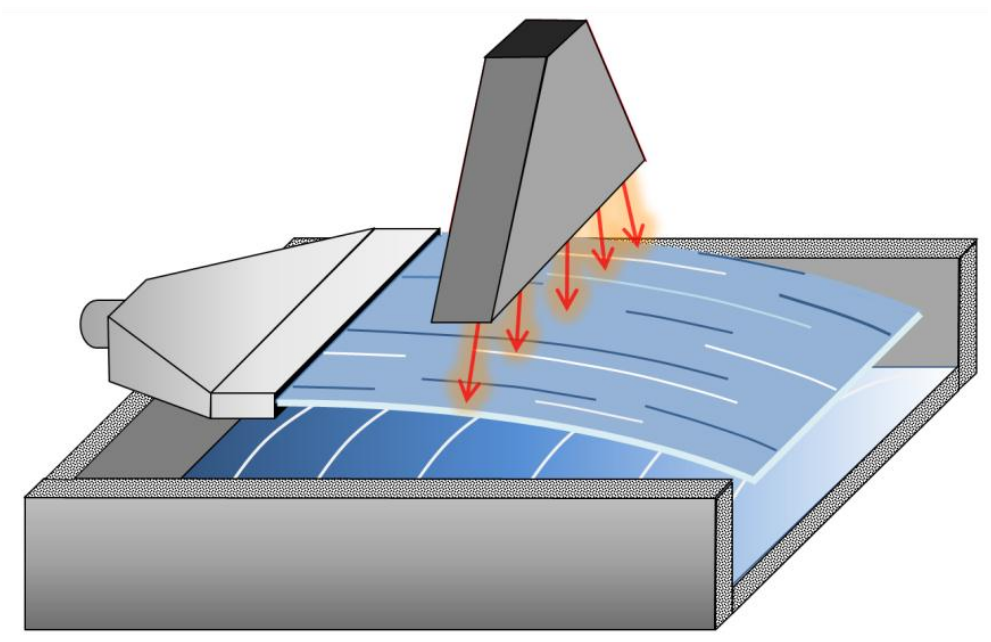

Figure S13. Jet reactor

a

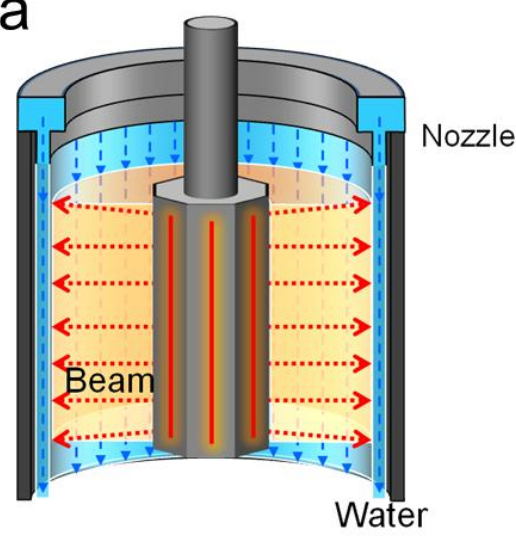

b

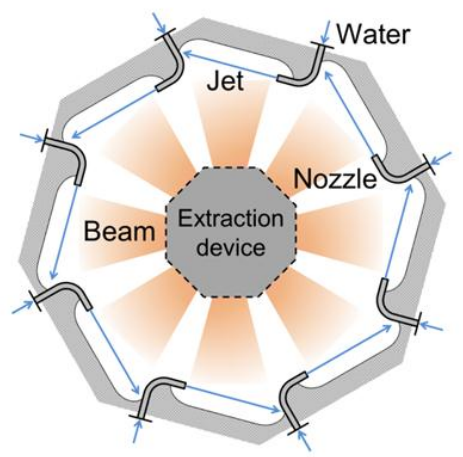

C

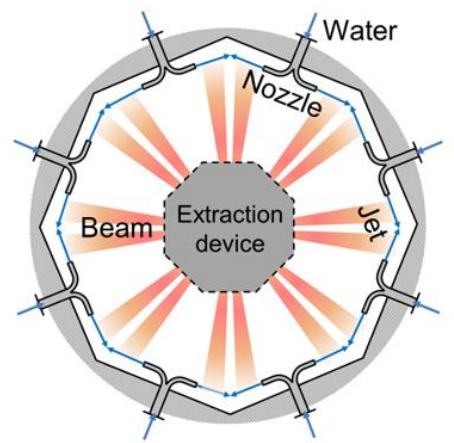

Figure S14. Schemes of a cylindrical reactor for the MWA accelerator with vertical beam scanning: a when the directions of water jet and beam scanning coincide (vertical section, $B=8-12 \mathrm{~m}$ ); $\mathrm{b}, \mathrm{c}$ - when the directions of water jets and beam scanning intersect, $b$ - unidirectional jets (top view, $B=20 \mathrm{~m}$ ) and bidirectional jets (c, top view, $B=40 \mathrm{~m}$ ) 


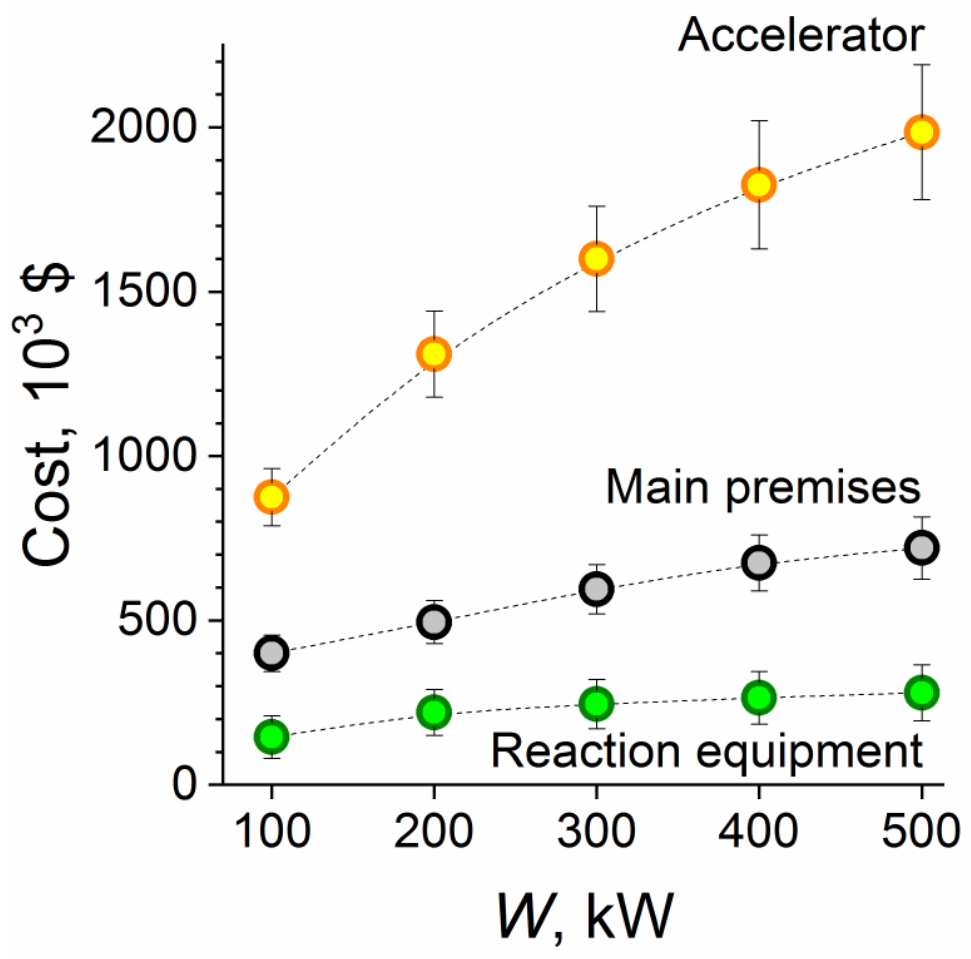

Figure S15. Capital expenditures for the accelerator, main premises and reaction equipment, depending on the power of the accelerator $W$

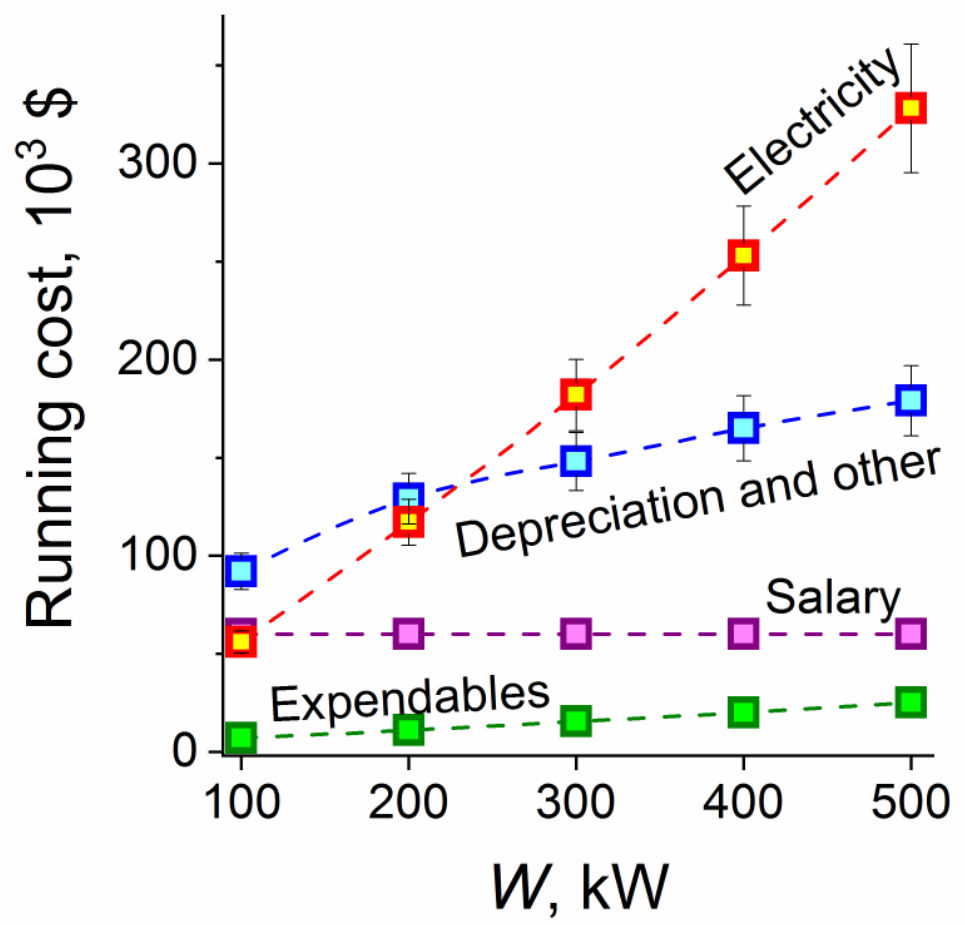

Figure S16. Annual running costs depending on the power of the accelerator $W$ 


\section{References}

1. Abdel Daiem, M. M.; Rivera-Utrilla, J.; Ocampo-Pérez, R.; Sánchez-Polo, M.; López-Peñalver, J. J. Treatment of Water Contaminated with Diphenolic Acid by Gamma Radiation in the Presence of Different Compounds. Chem. Eng. J. 2013, 219, 371-379. https://doi.org/10.1016/j.cej.2012.12.069.

2. Alkhuraiji, T. S.; Karpel Vel Leitner, N. Effect of Oxidant Addition on the Elimination of 2Naphthalenesulfonate in Aqueous Solutions by Electron Beam Irradiation. Radiat. Phys. Chem. 2016, 126, 95-102. https://doi.org/10.1016/j.radphyschem.2016.05.016.

3. Alkhuraiji, T. S.; Boukari, S. O. B.; Alfadhl, F. S. Gamma Irradiation-Induced Complete Degradation and Mineralization of Phenol in Aqueous Solution: Effects of Reagent. J. Hazard. Mater. 2017, 328, 29-36. https://doi.org/10.1016/j.jhazmat.2017.01.004.

4. Bae, B.-U.; Jung, E.-S.; Kim, Y.-R.; Shin, H.-S. Treatment of Landfill Leachate Using Activated Sludge Process and Electron-Beam Radiation. Water Res. 1999, 33 (11), 2669-2673. https://doi.org/10.1016/S0043-1354(98)00488-6.

5. Chmielewski, A. G. Electron Accelerators for Environmental Protection. Rev. Accel. Sci. Technol. Accel. Appl. Ind. Environ. 2012, 147-159. https://doi.org/10.1142/S1793626811000501.

6. Chu, L.; Wang, J. Degradation of 3-Chloro-4-Hydroxybenzoic Acid in Biological Treated Effluent by Gamma Irradiation. Radiat. Phys. Chem. 2016, 119, 194-199. https://doi.org/10.1016/j.radphyschem.2015.10.016.

7. Cleland, M. R.; Fernald, R. A.; Maloof, S. R. Electron Beam Process Design for the Treatment of Wastes and Economic Feasibility of the Process. Radiat. Phys. Chem. 1984, 24 (1), 179-190. https://doi.org/10.1016/0146-5724(84)90015-3.

8. Engohang-Ndong, J.; Uribe, R. M.; Gregory, R.; Gangoda, M.; Nickelsen, M. G.; Loar, P. Effect of Electron Beam Irradiation on Bacterial and Ascaris Ova Loads and Volatile Organic Compounds in Municipal Sewage Sludge. Radiat. Phys. Chem. 2015, 112, 6-12. https://doi.org/10.1016/j.radphyschem.2015.02.013.

9. Ershov, B. G. Kinetics, Mechanism and Intermediates of Some Radiation-Induced Reactions in Aqueous Solutions. Russ. Chem. Rev. 2004, 73 (1), 101-113. https://doi.org/10.1070/RC2004v073n01ABEH000865.

10. Guo, Z.; Zhou, F.; Zhao, Y.; Zhang, C.; Liu, F.; Bao, C.; Lin, M. Gamma Irradiation-Induced Sulfadiazine Degradation and Its Removal Mechanisms. Chem. Eng. J. 2012, 191, 256-262. https://doi.org/10.1016/j.cej.2012.03.012.

11. Han, B.; Kim, J.; Kim, Y.; Choi, J. S.; Makarov, I. E.; Ponomarev, A. V. Electron Beam Treatment of Textile Dyeing Wastewater: Operation of Pilot Plant and Industrial Plant Construction. Water Sci. Technol. 2005, 52 (10-11), 317-324. https://doi.org/10.2166/wst.2005.0708.

12. Han, B.; Kyu Kim, J.; Kim, Y.; Seung Choi, J.; Young Jeong, K. Operation of Industrial-Scale Electron Beam Wastewater Treatment Plant. Radiat. Phys. Chem. 2012, 81 (9), 1475-1478. https://doi.org/10.1016/j.radphyschem.2012.01.030.

13. Han, B.; Kim, J.; Kang, W.; Choi, J. S.; Jeong, K. Y. Development of Mobile Electron Beam Plant for Environmental Applications. Radiat. Phys. Chem. 2016, 124, 174-178. https://doi.org/10.1016/j.radphyschem.2015.12.014.

14. IAEA \& IIA. Industrial Radiation Processing with Electron Beams and X-Rays.; Berejka, A. J., Cleland, M. R., Eds.; IAEA \& IIA: Vienna, 2011.

15. IAEA. Achievements in the Removal of Biohazardous Pollutants by Radiation. Report of IAEA Technical Meeting, 8 - 12 July, 2019; IAEA: Lisbon, Portugal, 2019.

16. Ivanov, A. .; Ovchinnikov, V. .; Svinin, M. .; Tolstun, N. .; Bogart, S. . 4MeV High-Voltage Accelerator with 500kW Electron Beam for Radiation Sterilization. Vacuum 2001, 62 (2-3), 225-231. https://doi.org/10.1016/S0042-207X(01)00111-7.

17. Kovács, K.; He, S.; Míle, V.; Földes, T.; Pápai, I.; Takács, E.; Wojnárovits, L. Ionizing Radiation Induced Degradation of Monuron in Dilute Aqueous Solution. Radiat. Phys. Chem. 2016, 124, 191-197. https://doi.org/10.1016/j.radphyschem.2015.10.028.

18. Kuksanov, N. K.; Salimov, R. A.; Fadeev, S. N.; Nemytov, P. I.; Golubenko, Y. I.; Korgachin, A. I.; Lavruchin, A. V.; Semenov, A. V.; Cherepkov, V. G.; Kogut, D. A.; et al. Current Status of DC High Power ELV Electron Accelerators. Electrotech. Electron. 2018, 53 (7-8), 165-170. 
19. Lim, S. J.; Kim, T.-H. Advanced Treatment of Gamma Irradiation Induced Livestock Manure Using Bioelectrochemical lon-Exchange Reactor. J. Environ. Manage. 2018, 218, 148-153. https://doi.org/10.1016/j.jenvman.2018.04.054.

20. Makarov, I. E.; Ponomarev, A. V.; Han, B. Demonstration Plant for Electron-Beam Treatment of Taegu Dye Industry Complex Wastewater. In Emerging applications of radiation processing. IAEATECDOC-1386; IAEA, 2003; pp 138-152.

21. Makarov, I. E.; Ponomarev, A. V. Radiation-Induced Degradation of Organic Compounds and Radiation Technologies for Purification of Aqueous Systems. In lonizing Radiation Effects and Applications; InTech, 2018. https://doi.org/10.5772/intechopen.72074.

22. Meeroff, D. E.; Bloetscher, F.; Shaha, B. Economics of Wastewater/Biosolids Treatment by Electron Beam Technology. Radiat. Phys. Chem. 2019, 168, 108541. https://doi.org/10.1016/j.radphyschem.2019.108541.

23. Micro D10 reference data http://www.irradiationpanel.org/app/download/6497933/ Micro_D10_referencedata.xls.

24. Montgomery, J. M. Water Treatment Principles and Design.; Wiley: New York, 1985.

25. Okunieff, P.; Swarts, S.; Keng, P.; Sun, W.; Wang, W.; Kim, J.; Yang, S.; Zhang, H.; Liu, C.; Williams, J. P.; et al. Antioxidants Reduce Consequences of Radiation Exposure. In Advances in Experimental Medicine and Biology; Springer US: Boston, MA, 2008; Vol. 614, pp 165-178. https://doi.org/10.1007/978-0-387-74911-2_20.

26. Paul, J.; Naik, D. B.; Bhardwaj, Y. K.; Varshney, L. Studies on Oxidative Radiolysis of Ibuprofen in Presence of Potassium Persulfate. Radiat. Phys. Chem. 2014, 100, 38-44. https://doi.org/10.1016/j.radphyschem.2014.03.016.

27. Pikaev, A. K. Current Status of the Application of Ionizing Radiation to Environmental Protection: I. lonizing Radiation Sources, Natural and Drinking Water Purification (A Review). High Energy Chem. 2000, 34 (1), 1-12. https://doi.org/10.1007/BF02761780.

28. Pikaev, A. K. Mechanism of Radiation Purification of Polluted Water and Wastewater. Water Sci. Technol. 2001, 44 (5), 131-138. https://doi.org/10.2166/wst.2001.0269.

29. Pikaev, A. K. Radiation Chemistry and Radiation Technology at the Boundary of the Centuries: The Current Status and Prospects for Development. High Energy Chem. 2001, 35 (6), 367-388. https://doi.org/10.1023/A:1012505023625.

30. Pikaev, A. K.; Ponomarev, A. V.; Bludenko, A. V.; Minin, V. N.; Elizar'eva, L. M. Combined ElectronBeam and Coagulation Purification of Molasses Distillery Slops. Features of the Method, Technical and Economic Evaluation of Large-Scale Facility. Radiat. Phys. Chem. 2001, 61 (1), 81-87. https://doi.org/10.1016/S0969-806X(00)00377-7.

31. Pirogova, G. N.; Zhestkova, T. P.; Voronin, Y. V.; Panich, N. M.; Korosteleva, R. I.; Popova, N. N.; Byvsheva, I. I.; Pikaev, A. K. Radiolytic Gas Formation in Dilute Oxalic Acid Aqueous Solutions. High Energy Chem. 2002, 36 (5), 287-289. https://doi.org/10.1023/A:1020282230303.

32. Podzorova, E. A. Combined Radiation Methods for Water and Wastewater Treatment, Doct. Diss. Russian Academy of Sciences, 2001.

33. Ponomarev, A. V. Principles of Wastewater Treatment by Electron Beam. In Dyeing wastewater treatment using an electron accelerator; Taegu, Republic Korea, 2000; pp 5-17.

34. Ponomarev, A. V. Radiolytic Transformations in Multicomponent Organic and Aqueous-Organic Systems. Doct. Diss., Russian Academy of Sciences, 2004.

35. Ponomarev, A. V. High-Speed Electron-Beam Water Treatment: A Technological Consideration. Radiat. Phys. Chem. 2020, 172, 108812. https://doi.org/10.1016/j.radphyschem.2020.108812.

36. Shen, Y.; Chu, L.; Zhuan, R.; Xiang, X.; Sun, H.; Wang, J. Degradation of Antibiotics and Antibiotic Resistance Genes in Fermentation Residues by Ionizing Radiation: A New Insight into a Sustainable Management of Antibiotic Fermentative Residuals. J. Environ. Manage. 2019, 232, 171-178. https://doi.org/10.1016/j.jenvman.2018.11.050.

37. State Water Resources Control Board. Investigation on the Feasibility of Developing Uniform Water Recycling Criteria for DPR. 2016, 43. 
37. Szabó, L.; Tóth, T.; Homlok, R.; Rácz, G.; Takács, E.; Wojnárovits, L. Hydroxyl Radical Induced Degradation of Salicylates in Aerated Aqueous Solution. Radiat. Phys. Chem. 2014, 97, 239-245. https://doi.org/10.1016/j.radphyschem.2013.11.039.

39. Tolstun, N. G.; Ivanov, A. S.; Ovchinnikov, V. P.; Svinin, M. P. Further Development of Irradiation Field Forming Systems of Industrial Electron Accelerators. In EPAC 2006, Edinburgh, Scotland; Edinburgh, Scotland, 2006; pp 2005-2007.

40. Tolstun, N. G.; Efremov, A. V.; Ivanov, A. S.; Kuzhlev, A. N.; Maznev, V. P.; Machecha, A. I.; Ovchinnikov, V. P.; Pavluhov, D. E.; Svinin, M. P.; Solnyshkov, D. A. Development and Testing of Powerful High-Voltage Electron Accelerator for Energy-Intensive Industries. In 24th Russian Particle Accelerator Conference, RuPAC 2014; Obninsk, Russia, 2014; pp 327-329.

41. Wang, J.; Chu, L. Irradiation Treatment of Pharmaceutical and Personal Care Products (PPCPs) in Water and Wastewater: An Overview. Radiat. Phys. Chem. 2016, 125, 56-64. https://doi.org/10.1016/j.radphyschem.2016.03.012.

42. Wojnárovits, L.; Takács, E. Wastewater Treatment with lonizing Radiation. J. Radioanal. Nucl. Chem. 2017, 311 (2), 973-981. https://doi.org/10.1007/s10967-016-4869-3.

43. Woods, R.; Pikaev, A. Applied Radiation Chemistry. Radiation Processing.; Wiley: NY, 1994.

44. Zheng, B. G.; Zheng, Z.; Zhang, J. B.; Luo, X. Z.; Wang, J. Q.; Liu, Q.; Wang, L. H. Degradation of the Emerging Contaminant Ibuprofen in Aqueous Solution by Gamma Irradiation. Desalination 2011, 276 (1-3), 379-385. https://doi.org/10.1016/j.desal.2011.03.078. 